\title{
PREVALENCE OF ROTAVIRUS GASTROENTERITIS IN HOSPITALIZED UNDER-5 YEARS CHILDREN IN A TERTIARY CARE HOSPITAL OF MANSOURA-EGYPT
}

\author{
$\mathscr{B}_{y}$ \\ Wael Seliema,b, MS,MD, Amira M. Sultana,c, \\ MS,MD, Nawal S. Goudaa,c, MS,MD \\ Fram \\ Wael Seliem ${ }^{a, b}$, MS,MD, Amira M. Sultan a,c, MS,MD, Nawal S. Gouda a,c, MS,MD \\ aMansoura University - Faculty of Medicine, bPediatric Department, \\ cMedical Microbiology and Immunology Department - Egypt.
}

\begin{abstract}
Rotavirus is responsible for a significant gastrointestinal disease primarily in children less than 5 years of age worldwide causing massive morbidity and mortality. This study aimed to identify the proportion of children with acute gastroenteritis infected with rotavirus through systematic sampling over a 1-year period in a tertiary care hospital, Mansoura University Children's Hospital - Mansoura-Egypt
\end{abstract}

\section{Patients and Methods}

This study included all hospitalized children aged less than 5 years who presented with acute watery diarrhea. Collected stool samples were tested for the presence of 259 rotavirus using an ELISA kit.

\section{Results}

Out of 385 stool samples, rotavirus antigen was detected in the stool samples of 144 (37.4\%), of which 74 $(45.9 \%)$ samples were from infants in the age group of $0-12$ months. Fever was found to be significantly more frequent among children with rotavirus positive samples $[86.5 \%$ vs. $55.7 \%, P=0.02$ ]. The same was found with vomiting as it was more frequent among children with rotavirus positive samples $[80 \%$ vs. $67.7 \%, P=0.05]$. Severe dehydration was significantly more common in patients with rotavirus infection [31.9\% vs. $18 \%, P=0.02$ ], while mild and moderate dehydration did not MANSOURA MEDICAL JOURNAL 
show the same level of significance [17\% vs. 22.5, $P=0.42]$ and [51\% vs. $59.4 \%, P=0.74]$ respectively. Rotavirus positive cases aged less than one year were found to present with a severe degree of dehydration 34 $(45.9 \%)$ while moderate degree of dehydration was most frequently presented among other age groups indicating that the younger the age the more the severity of symptoms of rotavirus infection.

\section{INTRODUCTION}

Rotavirus is considered a predominant etiologic factor for acute gastroenteritis which can be severe enough necessitating hospital admission among children globally [1]. It accounts for an aggressive gastrointestinal illness chiefly in children aged $<5$ years all over the world leading to a considerably higher morbidity and mortality rates particularly in the developing countries [2]. Rotavirus modifies the function of small intestinal epithelium resulting in enterocyte destruction and subsequently diarrhea with malabsorption [3]. The disease severity can be affected by both viral and host factors which explain cases of symptoms-free rotavirus infections that have been previ- ously reported among all age groups [4].

The mucosal immune system is considered a valuable defense mechanism which has the ability to protect the gastrointestinal mucosal surface against invasion by potentially harmful pathogens $[5,6]$. The impaired sodium and glucose absorption is the reason behind diarrhea caused by rotavirus infection, as the non-absorbing immature crypt cells have replaced the damaged cells on intestinal villi [7]. Exposure to infection occurs in early life as almost $90 \%$ of children 3 years or less of age have detectable serum antibodies against rotavirus, indicating high levels of exposure [1].

This study aimed to identify the proportion of children with acute gastroenteritis infected with rotavirus through systematic sampling of hospitalized children under 5-years in a tertiary care hospital in MansouraEgypt over a period of one year.

\section{PATIENTS AND METHODS}

The current study was conducted in a tertiary care hospital, Mansoura University Children's Hospital - Man- 
soura-Egypt, from September 2012 to September 2013. This study included all children $<5$ years who presented with acute watery diarrhea and required hospital admission. $A$ written consent was obtained for each child from the respective guardian after explaining the purpose of the study. Diarrhea was defined when there was an increase in the stool frequency in comparison with the regular habit of a child less than 5 years [7]. If a child has experienced 3 or more bouts of watery or looser-than usual stools and/or projectile vomiting within 24 hours through the previous 3 days period, gastroenteritis is considered as defined by the WHO [8]. Clinical data including age, sex, duration of illness, number of stools, associated vomiting and fever, degree of dehydration, and concomitant illness were recorded on a standardized case reporting form. An institutional Ethical Committee approval was obtained prior to commencement of the study.

Exclusion criteria included infants with history of gastrointestinal surgical procedures, suspected extra intestinal causes of diarrhea, previ- ous immunosuppressive therapy and infants who received rotavirus vaccine.

Stool specimens from all hospitalized children aged under 5 years who presented with acute watery diarrhea were collected, transported in iceboxes and stored at $-20^{\circ} \mathrm{C}$. Rotavirus detection in the collected stool specimens were conducted by means of an antigen detection apparatus, the enzyme-linked immunosorbent assay (ELISA) (Premier TM Rotaclone ${ }^{\circledR}$, Meridian Biosciences, Cincinnati, Ohio, USA), as per kit protocol. An internal control was included in all runs, and the run was repeated if the internal control did not fall in the expected range. The same stool samples were also tested for the detection of any secondary bacterial infection through routine microbiological diagnosis. The onset and duration of clinical manifestations were recorded. The clinical degree of dehydration was classified into mild, moderate and severe by means of a clinical scoring scheme [9].

The rotavirus negative stool samples were further processed for de-

MANSOURA MEDICAL JOURNAL 
termining the cause of diarrhea. Samples were tested for other microbiological causes through culture and sensitivity test [10]. Parasitic infections in the samples were diagnosed by routine microscopy [11]. Lactose intolerance was detected by Benedict test [12].

\section{Statistical Analysis}

Study data were initially captured into Microsoft Excel program then exported into Statistical Package for Social Sciences (SPSS, Version 15) for editing and statistical analysis [Chicago, IL, USA]. The $\mathrm{P}$ value < 0.05 was considered significant.

\section{RESULTS}

Of the total 385 stool samples collected, 161 from age group 0-12 months, 89 from age group 13-24 months, 68 from age group 25-36 months, 43 from age group 37-48 months and 24 from age group 49-60 months. Rotavirus antigen was detected in 144 (37.4\%) samples of which $74 / 161$ (45.9\%) from the age group 0-12 months, 31/89 (34.8\%) from the age group 13-24 months, $23 / 68$ (33.8\%) from the age group 25-36 months, 11/43 (25.6\%) from the age group 37-48 months and 5/25 (20.8\%) from age group 49-60 months (Table 1).

As many as 43 rotavirus positive stool samples were concomitantly tested for the presence of secondary bacterial infection. Pathogenic bacteria identified were Klebsiella species, Enterobacter species, Shigella species and Escherichia coli. The majority of cases with secondary bacterial infections in the stool samples (28 cases) were found in the age group from 0-12 month. Eight cases were found in the 13-24 month group, 4 cases aged 25-36 month and 3 cases were found in the 37-48 month group. Stool samples from patients in the 49-60 months group did not have any secondary bacterial infection.

The clinical manifestations occurring in children with gastroenteritis were recorded in Table 2. Fever was found to be significantly more frequent among children with rotavirus positive samples [85.4\% vs. $56.4 \%$, $\mathrm{P}=0.02]$. The same was found with vomiting as it was more frequent among children with rotavirus positive samples $[80.5 \%$ vs. $68.5 \%$, $\mathrm{P}=0.05]$. Severe dehydration was significantly common among patients 
with rotavirus infection $[31.3 \%$ vs less than one year were found to $18.3 \%, P=0.02$ ], while mild and mod- present with severe dehydration erate dehydration did not show the $(45.9 \%)$ while a moderate degree same level of significance [16.7\% vs. of dehydration was most frequently $22.8 \%, P=0.42]$ and $[52.1 \%$ vs. presenting among other age groups $60.2 \%, P=0.74]$ respectively.

The most frequent clinical manifestations recorded among rotavirus positive cases in the age group 0-12 months were fever, vomiting and severe dehydration $(95.9 \%, 97.3 \%$ and $45.9 \%$ respectively) when compared to other age group categories as shown in Table 3.

Rotavirus positive cases aged indicating that the younger the age the more aggressive the symptoms of rotavirus infection as shown in Table 3.

The number of days of hospitalization in rotavirus infected children under- 5 years of age has been shown in Table 4. No seasonal prevalence of rotavirus diarrhea has been detected as shown in Figure 1.

Table 1: Distribution of rotavirus positive stool samples of hospitalized under-5 years children.

\begin{tabular}{lccc}
\hline Age & $\begin{array}{c}\text { Samples } \\
\text { Obtained }\end{array}$ & $\begin{array}{c}\text { Rotavirus positive } \\
\text { patients }\end{array}$ & $\begin{array}{c}\text { Secondary bacterial } \\
\text { infection }\end{array}$ \\
(month) & 161 & $74(45.9 \%)$ & $28(37.8 \%)$ \\
\hline $\mathbf{0 - 1 2}$ & 89 & $31(34.8 \%)$ & $8(25.8 \%)$ \\
$\mathbf{1 3 - 2 4}$ & 68 & $23(33.8 \%)$ & $4(17.4 \%)$ \\
$\mathbf{2 5 - 3 6}$ & 43 & $11(25.6 \%)$ & $3(27.3 \%)$ \\
$\mathbf{3 7 - 4 8}$ & 24 & $5(20.8 \%)$ & $0(0.0 \%)$ \\
$\mathbf{4 9 - 6 0}$ & 385 & $144(37.4 \%)$ & $43(29.9 \%)$ \\
Total & & & \\
\hline
\end{tabular}


Table 2: The clinical picture and hospital stay in rotavirus positive and negative children.

\begin{tabular}{lccc}
\hline \multicolumn{1}{c}{ Variable } & $\begin{array}{c}\text { Rotavirus Positive } \\
(\mathbf{N}=144)\end{array}$ & $\begin{array}{c}\text { Rotavirus Negative } \\
(\mathbf{N}=\mathbf{2 4 1})\end{array}$ & $P$ value \\
\hline Age in months (CI) & $11.8(9.1-12.7)$ & $15.9(13.5-17.1)$ & 0.09 \\
\hline Fever (\%) & $123(85.4 \%)$ & $136(56.4 \%)$ & 0.02 \\
Vomiting (\%) & $116(80.5 \%)$ & $165(68.5 \%)$ & 0.05 \\
Mild dehydration (\%) & $24(16.7 \%)$ & $55(22.8 \%)$ & 0.42 \\
\hline Moderate dehydration $(\%)$ & $75(52.1 \%)$ & $145(60.2 \%)$ & 0.74 \\
\hline Severe dehydration $(\%)$ & $45(31.3 \%)$ & $44(18.3 \%)$ & 0.02 \\
\hline Days of stay (CI) & $5.3(4.6-7.1)$ & $4.5(3.9-6.7)$ & 0.32 \\
\hline
\end{tabular}

Table 3: Distribution of clinical features in rotavirus infected children under-5 years.

\begin{tabular}{|c|c|c|c|c|c|c|c|}
\hline & & Rotavirus & & Vomiting & & Dehydration & \\
\hline $\begin{array}{l}\text { group } \\
\text { (month }\end{array}$ & obtained & & $(\%)$ & & Mild & Moderate & Severe \\
\hline $0-12$ & 161 & $74(45.9 \%)$ & $71(95.9 \%)$ & $72(97.3 \%)$ & $8(10.8 \%)$ & $32(43.2 \%)$ & $34(45.9 \%)$ \\
\hline $13-24$ & 89 & $31(34.8 \%)$ & $26(83.9 \%)$ & $24(77.4 \%)$ & $7(22.6 \%)$ & $17(54.8 \%)$ & $7(22.6 \%)$ \\
\hline 25-36 & 68 & $23(33.8 \%)$ & $16(69.6 \%)$ & $13(56.5 \%)$ & $5(21.7 \%)$ & $15(65.2 \%)$ & $3(13.0 \%)$ \\
\hline $37-48$ & 43 & $11(25.6 \%)$ & $7(63.6 \%)$ & $5(45.5 \%)$ & $3(27.3 \%)$ & $7(63.6 \%)$ & $1(9.1 \%)$ \\
\hline $49-60$ & 24 & $5(20.8 \%)$ & $3(60.0 \%)$ & $2(40.0 \%)$ & $1(20.0 \%)$ & $4(80.0 \%)$ & $0(0.0 \%)$ \\
\hline Total & 385 & $144(37.4 \%)$ & $123(85.4 \%)$ & $116(80.6 \%)$ & $24(16.7 \%)$ & $75(52.1 \%)$ & $45(31.3 \%)$ \\
\hline
\end{tabular}

Vol. 43, No. 1 \& 2 Jan. \& April, 2014 
Table 4: Distribution of days of hospitalization in rotavirus infected children under-5 years.

\begin{tabular}{lcccc}
\hline Age group & Rotavirus positive & \multicolumn{3}{c}{ Days of hospitalization } \\
\cline { 3 - 5 } (month) & & $\mathbf{3}$ days (\%) & $\mathbf{3 - 6}$ days (\%) & $\geq 7$ days (\%) \\
$\mathbf{0 - 1 2}$ & 74 & $13(17.6 \%)$ & $43(58.1 \%)$ & $18(24.3 \%)$ \\
$\mathbf{1 3 - 2 4}$ & 31 & $8(25.8 \%)$ & $18(58.1 \%)$ & $5(16.1 \%)$ \\
$\mathbf{2 5 - 3 6}$ & 23 & $7(30.4 \%)$ & $11(47.8 \%)$ & $5(21.7 \%)$ \\
$\mathbf{3 7 - 4 8}$ & 11 & $6(54.5 \%)$ & $4(36.4 \%)$ & $1(9.1 \%)$ \\
$\mathbf{4 9 - 6 0}$ & 5 & $4(80.0 \%)$ & $1(20.0 \%)$ & $0(0.0 \%)$ \\
Total & 144 & $38(26.4 \%)$ & $77(53.5 \%)$ & $29(20.1 \%)$ \\
\hline
\end{tabular}

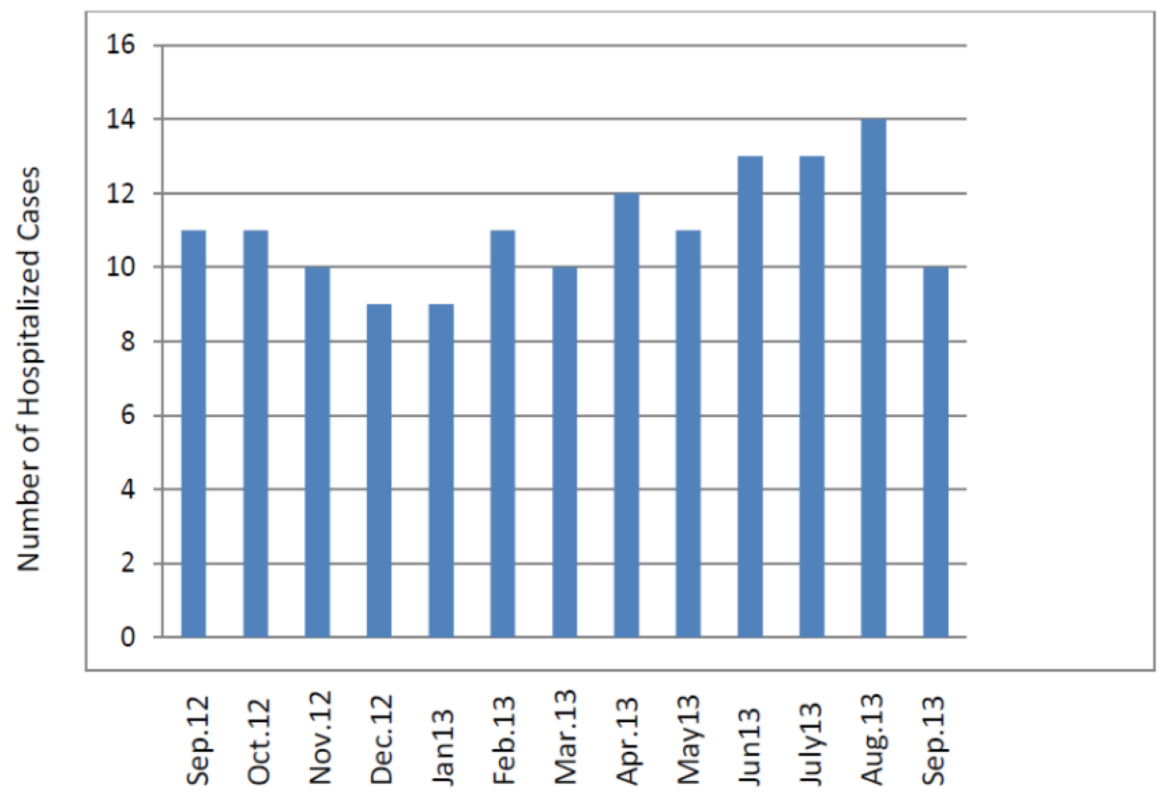

Figure 1: The distribution of hospitalized cases presenting with rotavirus diarrhea across the year. 
DISCUSSION

Rotavirus is disseminated by feco-oral route most commonly through close contact from person to another person and by infected fomites and less commonly through water and food. The virus can survive for long times in fomites unless disinfected $[13,14]$. This ensures that rotavirus diarrheal diseases are prevalent all the year round, although peak periods are observed during the winter months, October to February as noted in previous studies [15-17]. Ensuring good water quality and sanitary conditions do not have maximal effect in the control of rotavirus diarrhea; hence, the emphasis on immunization [13]. The methods of feeding and type of complementary feeding were not predictors of rotavirus diarrhea in children. Although contaminated food (which could be from the bottle) aids in transmission of rotavirus [18].

In the present study we found that gastroenteritis in $37.4 \%$ of the children aged less than 5 years were due to rotavirus. In reports from other developing countries such as India, rotavirus was identified in 39\% of stool samples collected from children aged under 5 years according to their surveillance network [19, 20]. Studies in other parts of Asia have shown a much higher prevalence rate [21].These may show that the epidemiology of rotavirus differs according to the locality, socioeconomic status and general living conditions.

In our study infants aged $<12$ months had a prevalence of $45.9 \%$ of rotavirus diarrhea with lower tendency among infants and children aged 13-24 months and 25-36 months $(34.8 \%$ and $33.8 \%$, respectively). These data are of great importance as lower prevalence of infection among the same age group in the developed countries, highlights the importance of rotavirus vaccination given to them alongside their compulsory primary immunization program in preventing the vast majority of infected cases. In our study the same as reports from developing countries, this age related prevalence is somewhat higher due to absence of vaccination set up and the majority of rotavirus cases occurred throughout the first year of life in hospital-based studies [21].

Regarding seasonality, an obvious seasonal variation was not

Vol. 43, No. 1 \& 2 Jan. \& April, 2014 
shown in our study and rotavirus gastroenteritis increased from March through August and was less during the rest of the year from September through February. Our study did not show any peering between rotavirus gastroenteritis and any time of year with an uneven distribution throughout the year, similar to previous reports from India [22, 23]. Other studies have shown significant increment of rotavirus- gastroenteritis during winter from October to February [2426]. Rotavirus was markedly seasonal in certain places such as northern India but with more tropical climate in southern locations, a less seasonal variation was reported [19, 27, 28]. Mixed infections are common, and it has been demonstrated that mixed infection with entero-toxic Escherichia coli and rotavirus caused a higher mortality than did either diseases, individually. In surveillance, co-infection of rotavirus and Escherichia coli (11.1-45.5\%), Salmonella species $(0.5-4.8 \%)$, Giardia species $(1.7-8.6 \%)$ and Shigella flexneri (3.2-8.0\%) had been recorded from Iran; also children who suffered from mixed infection have shown higher incidence of vomiting, dehydration and fever [29]. Mixed infections might result from unhealthy environments to a larger extent in urban slums; inoculate of more diverse serotypes of rotavirus along with enteropathogens prevalent in water or contaminated food are the determinative causatives [30]. In our study, although the duration of hospitalization of children under-5 years of age who suffered from rotavirus gastroenteritis was longer than those who suffered from non-rotavirus gastroenteritis, this difference did not show any statistical significance. Also, the majority of age groups included were hospitalized between 3 to 6 days.

There were a few limitations of the present study. As this study is hospital-based, the prevalence of rotavirus might have been different from the actual prevalence in the community. The incidence of the disease could not be calculated in this study.

\section{Conclusion}

Our study has made it quite clear that more than one-third of the diarrheal disorders among children aged under 5 years are due to rotavirus. Therefore, personal hygiene and hand washing practices among family members is of great importance to limit the spread of the disease and to

MANSOURA MEDICAL JOURNAL 
practice a very strict preventive measures in terms of compulsory vaccination against rotavirus.

\section{REFERENCES}

1. Centers for Disease Control and Prevention (CDC). (2008) : Rotavirus surveillance- worldwide, 20012008. MMWR Morb Mortal Wkly Rep.; 57:1255-7.

2. Parashar UD, Hummelman EG, Bresee JS, Miller MA and Glass RI. (2003) : Global illness and deaths caused by rotavirus disease in children. Emerg Infect Dis. 9 (5):565-72.

3. Kapikian AZ. (2001) : A rotavirus vaccine for prevention of severe diarrhea of infants and young children: development, utilization and withdrawal Novartis Found Symp. ; 238:153-71; discussion 171-9.

4. Ramig RF. 92004) : Pathogenesis of Intestinal and Systemic Rotavirus Infection. J Virol. Oct; 78(19): 10213-10220.

Vol. 43, No. 1 \& 2 Jan. \& April, 2014
5. Holmgren J, Czerkinsky C. (2005) : Mucosal immunity and vaccines. Nat Med.; 11(4 Suppl):S45-53.

6. Fagarasan S, Honjo T. (2003) : Intestinal IgA synthesis: regulation of front-line body defenses. Nat Rev Immunol.; 3 (1):63-72.

7. Mustafa NS, Elhag WI. (2013) : Diagnosis of rotavirus gastroenteritis by a latex agglutination test in Khartoum State, Sudan. J Pharm Biomed Sci ; 33:1594-8.

8. WHO. Diarrhea, Health topics, (2009) : Available at http:// www.who.int/topics/ diarrhoea/en/

9. King CK, Glass R, Bresee JS and Duggan C. (2003) : Managing acute gastroenteritis among children: oral rehydration, maintenance, and nutritional therapy. MMWR Recomm Rep.; 52 (RR-16): 1-16. PMid: 14627948

10. Sarma JB, Bhattacharya PK, 
Kalita D, Rajbangshi M.

(2011) : Multidrug-resistant Enterobacteriaceae including metallo-?-lactamase producers are predominant pathogens of healthcareassociated infections in an Indian teaching hospital. Indian $J$ Med Microbiol. 2011;29(1):22-7.

11. Magill AJ, Ryan ET, Solomon T, Hill DR. (2013) : Hunter's tropical medicine and emerging infectious disease. 9th ed. USA: Elsevier; .

12. Melvin BH. (2006) : Lactose intolerance in infants, children, and adolescents. Pediatrics ; 118:1279-86.

13. World Health Organization. (2009) : Introduction of Rotavirus Vaccines into National Immunization Programs - Management Manual, Including Operational Information for Health Workers. WHO/IVB/09.09. Department of Immunization, Vaccines and Biologicals;. Available from: http:// www.who.int/immunization/ en/. [Last accessed on 2012 Jun 05].

14. Centers for Disease Control and Prevention (CDC). (2009) : Prevention of rotavirus gastroenteritis among infants and children. Recommendations of the Advisory Committee on Immunization Practices (ACIP). MMWR; 58(No. RR-2):124.

15. World Health Organization. (2010) : Epidemiologic surveillance of diarrheal diseases due to rotavirus: Field guide. Immunization unit of the Pan American Health Organization;. Available from: http:// new.paho.org /hq/index. php? option = comcontent\&tas $\mathrm{k}=$ view \&id = $278 \&$ Itemid $=358$.

16. Tagbo BN, Mwenda JM, Armah G, Obidike EO, Okafor UH, Oguonu T, et al. (2014) : Epidemiology of rotavirus diarrhea among children younger than 5

MANSOURA MEDICAL JOURNAL 
years in Enugu, South

East, Nigeria. Pediatr Infect

Dis J; 33 Suppl 1:S19-22.

17. Gomwalk NE, Gosham LT, Umoh UJ. (1990) : Rotavirus gastroenteritis in pediatric diarrhea in Jos, Nigeria. J Trop Pediatr; 36:52-5.

18. Akoua-Koffi C, Asse Kouadio V, Yao Atteby JJ. (2014) : Hospital-based surveillance of rotavirus gastroenteritis among children under 5 years of age in the Republic of Ivory Coast: A crosssectional study. BMJ Open; 4:e003269.

19. Kang G, Arora R, Chitambar SD, Deshpande J, Gupte MD, Kulkarni M, et al. (2009) : Indian Rotavirus Strain Surveillance Network. Multicenter, hospitalbased surveillance of rotavirus disease and strains among Indian children aged $<5$ years. J Infect Dis; 200:S147-53.

20. Kang G, Desai R, Arora R,
Chitamabar S, Naik TN, Krishnan T, et al. (2013) : Diversity of circulating rotavirus strains in children hospitalized with diarrhea in India, 2005-2009. Vaccine.; 31(27) : 2879-83.

21. Nelson EA, Bresee JS, Parashar UD, Widdowson MA, Glass RI; Asian Rotavirus Surveillance Network. (2008) : Rotavirus epidemiology: The Asian rotavirus surveillance network. Vaccine; 26:3192-6.

22. Banerjee I, Ramani S, Primrose $B$, Moses $P$, IturrizaGomara M, Gray JJ, et al. (2006) : Comparative study of the epidemiology of rotavirus in children from a community based birth cohort and a hospital in South India. J Clin Microbiol; 44:2468-74.

23. Mukherjee A, Chattopadhyay S, Bagchi P, Dutta D, Singh NB, Arora R, et al. (2010) : Surveillance and molecular characterization of rotavirus strains circulat- 
ing in Manipur, northeastern India: Increasing prevalence of emerging G12 strains. Infect Genet Evol;10:311-20.

24. Bahl R, Ray P, Subodh S, Shambharkar $\mathbf{P}$, Saxena M, Parashar U, et al. (2005) : Delhi Rotavirus Study Group. Incidence of severe rotavirus diarrhea in New Delhi, India, and G and $P$ types of the infecting rotavirus strains. $J$ Infect Dis ; 192(Suppl 1):S114-9.

25. Kahn G, Fitzwater S, Tate J, Kang G, Ganguly N, Nair G, et al. (2012) : Epidemiology and Prospects for Prevention of Rotavirus Disease in India. Indian Pediatrics; 49: 469.

26. Saravanan $P$, Ananthan $S$, Ananthasubramanian $M$. (2004) : Rotavirus infection among infants and young children in Chennai, South India. Indian J Med Microbiol; 22:212-21.

27. Ray P, Sharma S, Agarwal
RK, Longmei K, Gentsch JR, Paul VK, et al. (2007) : First detection of G12 rotaviruses in newborns with neonatal rotavirus infection at all India Institute of Medical Sciences, New Delhi, India. J Clin Microbiol; 45:3824-7.

28. Phukan AC, Patgiri DK, Mahanta J. (2003) : Rotavirus associated acute diarrhea in hospitalized children in Dibrugarh, North-east India. Indian J Pathol Microbiol; 46:274-8.

29. Grimprel E, Rodrigo C, Desselberge U. (2008) : Rotavirus disease, impact of coinfections. Pediatr Infect Dis J; 27(1):3-10.

30. Ataei-Pirkooh A, ShamsiShahrabadi M, HaghiAshtiani MT. (2011) : Incidence of coinfection between rotavirus and some enteropathogenic agents in children referred to children medical centre hospital, Tehran, 2009. Iranian J Virol; 5(1):23-7.

MANSOURA MEDICAL JOURNAL 